\title{
Rates of metachronous adenoma after curative resection for left-sided or right-sided colon cancer
}

\author{
Yuk Fai Lam ${ }^{1}$, Wai Kay Seto ${ }^{1}$, Teresa Tong ${ }^{1}$, Ka Shing Cheung ${ }^{1}$, Oswens Lo ${ }^{2}$, Ivan FN Hung ${ }^{1}$, Wai Lun Law ${ }^{2}$, \\ Wai K Leung ${ }^{1}$ \\ Departments of ${ }^{I}$ Medicine and ${ }^{2}$ Surgery, Queen Mary Hospital, The University of Hong Kong, Hong Kong
}

\begin{abstract}
Background/Aims: We determined the rates of metachronous colorectal neoplasm in colorectal cancer (CRC) patients after resection for right (R)-sided or left (L)-sided cancer. Methods: Consecutive CRC patients who had undergone surgical resection for curative intent in our hospital between 2001 and 2004 were identified. R-sided colonic cancers refer to cancer proximal to splenic flexure whereas L-sided cancers include rectal cancers. Patients were included only if they had a clearing colonoscopy performed either before or within 6 months after the operation. Findings of surveillance colonoscopy performed up to 5 years after colonic resection were included in the analysis. Results: Eight hundred and sixty-three CRC patients underwent curative surgical resection during the study period. Three hundred and twenty-seven patients (107 R-sided and $220 \mathrm{~L}$-sided) fulfilled the inclusion criteria and had at least 1 postoperative surveillance colonoscopy performed. The proportion of patients who had polyp and adenoma on surveillance colonoscopy was significantly higher among patients with L-sided than R-sided cancers (polyps: $30.9 \%$ vs. $19.6 \%, P=0.03$; adenomas: $25.5 \%$ vs. $13.1 \%, P=0.01$ ). The mean number of adenoma per patient on surveillance colonoscopy was also higher for patients with L-sided than R-sided tumors $(0.52 ; 95 \%$ confidence interval [CI], $0.37-0.68$ vs. $0.22 ; 95 \%$ CI, $0.08-0.35 ; P<0.01)$. Multivariate analysis showed that L-sided cancers, age, male gender and longer follow-up were independent predictors of adenoma detection on surveillance colonoscopy. Conclusions: Patients with Lsided cancer had a higher rate of metachronous polyps and adenoma than those with R-sided cancer on surveillance colonoscopy. (Intest Res 2018;16:619-627)
\end{abstract}

Key Words: Colonoscopy; Colon neoplasms; Curative colectomy; Follow up; Recurrence

\section{INTRODUCTION}

Surveillance colonoscopy plays a pivotal role in monitoring of colorectal cancer (CRC) patients after surgical resection, which enables early detection of recurrent cancer as well as metachronous lesions such as polyp or adenoma. Regular surveillance colonoscopy together with other surveillance strategies can detect recurrence at earlier stage and improve survival of CRC patients. ${ }^{1,2}$

Although the majority of CRCs develop through the con-

Received February 5, 2018. Revised March 27, 2018.

Accepted May 3, 2018.

Correspondence to Wai K Leung, Department of Medicine, Queen Mary

Hospital, The University of Hong Kong, 102 Pokfulam Road, Hong Kong. Tel

+852-2255-3348, Fax: +852-2816-2863, E-mail: waikleung@hku.hk ventional adenoma-carcinoma sequence, ${ }^{3,4}$ there are a certain proportion of right (R)-sided colon cancers that progress through the serrated neoplastic pathway. In view of the diversity in molecular pathogenesis of CRC, it is highly plausible that the rates of metachronous neoplasms in patients after curative resection for R- or left (L)-sided colon cancers are different.

Studies focusing on the development of pre-cancerous lesions after resection of CRC showed that advanced age and the presence of synchronous neoplasm were associated with development of metachronous neoplasms. ${ }^{5-7}$ Although previous studies have evaluated the risk factors for development of metachronous $\mathrm{CRC}^{8-11}$ there was a paucity of data on the association between the sites of primary tumor and subsequent risk of metachronous adenoma or polyp. Fuc-

- Copyright 2018. Korean Association for the Study of Intestinal Diseases. All rights reserved.

This is an Open Access article distributed under the terms of the Creative Commons Attribution Non-Commercial License (http://creativecommons.org/licenses/by-nc/4.0)

which permits unrestricted non-commercial use, distribution, and reproduction in any medium, provided the original work is properly cited. 
cio et al. ${ }^{12}$ showed that patients with L-sided primary tumor had a higher risk of metachronous adenoma after surgical resection, suggesting a different rate of metachronous lesions development. However, patients with rectal carcinoma, who are known to be at risk of local recurrence, were not included in their study and the analysis was also limited to the second surveillance colonoscopy only. Current guidelines on surveillance after colorectal resection recommend surveillance colonoscopy to be performed 1 year after surgical resection, and then repeat at 3 to 5 years. ${ }^{13-16}$ As yet, patients' factors, particularly with regards to primary tumor location, were not taken into account when considering the optimal surveillance interval.

In this study, we determined the risk of subsequent adenoma and polyp development in patients after curative resection for L- or R-sided cancer. We also considered the potential confounding effects of age, sex, family history of CRC, aspirin or statin use, stage and site of tumor as well as the duration of follow-up period on the rate of metachronous neoplasms. Our finding may help to tailor the best surveillance strategy for CRC patients according to the site of primary tumor.

\section{METHODS}

\section{Patients}

This is a retrospective cohort study performed in the Queen Mary Hospital of Hong Kong, which is the regional hospital of the Hong Kong West Cluster of the Hospital Authority as well as the teaching hospital of the University of Hong Kong. We retrieved all CRC patients who had undergone curative resection in the department of surgery between January 2001 and December 2004. We only included patients who had a clearing colonoscopy with all polyps removed either before surgery or within 6 months after the operation to ensure the lesions detected on surveillance colonoscopy were metachronous but not previously missed lesions. Patients who had incomplete preoperative colonoscopy due to obstructing tumor but with all the proximal segments removed by surgery were also included in the analysis. Exclusion criteria included patients with (1) familial CRC syndrome including familial adenomatous polyposis syndrome and hereditary non-polyposis colorectal cancer syndrome; (2) IBD; (3) previous subtotal or total colectomy; (4) synchronous cancers at baseline; and (5) baseline cancer being a metachronous or recurrent cancer. All clinical information of individual patient was retrieved from the electronic patient record system of the Hospital Authority of Hong Kong, which is a centralized computer database used in all local public hospitals. The database included all operative and endoscopy records, histopathology and imaging findings, laboratory results, hospital discharge summary and outpatient consultation notes as well as prescription and dispensing records. ${ }^{17}$ For each patient, the following information were retrieved including baseline demographics, family history of $\mathrm{CRC}$, the stage and site of the primary tumor, the date and type of operation, use of aspirin and statin, all colonoscopy and sigmoidoscopy findings and their histopathology results.

Patients who had CRC in their first-degree relatives were considered to have positive family history. Patients who were on aspirin or statin at the time of operation and any time within 5 years after resection were considered to be aspirin and statin users, respectively. The stage of CRC was reported according to the American Joint Committee on Cancer Staging for CRC (the 6th edition). ${ }^{18}$ We included all colonoscopies and sigmoidoscopies performed from 6 to 60 months after surgical resection. All procedures were performed by experienced gastroenterologists, colorectal surgeons or trainees under supervision. For all colonoscopies, we recorded the date of procedure, the quality of bowel preparation and details of the lesions identified.

The study was approved by the Institutional Review Board (IRB No. UW 16-458) of the University of Hong Kong and the West Cluster of Hospital Authority of Hong Kong. As this is a retrospective cohort study, informed consent from individual patient could not be obtained and was waived by the IRB.

\section{Definition}

Advanced adenoma was defined as adenoma with highgrade dysplasia, villous component or of size $\geq 1 \mathrm{~cm} .{ }^{19}$ Serrated lesion was classified according to the World Health Organization (WHO) classification ${ }^{3,20}$ and included traditional serrated adenoma, sessile serrated adenoma with or without cytological dysplasia, and hyperplastic polyp. In this study, recurrent cancer was defined as cancer diagnosed at or near the anastomosis. Metachronous cancer was defined as cancer diagnosed at a site other than those at or near the anastomosis. For patients who developed recurrent CRC or metachronous $\mathrm{CRC}$, the information was censored from the time when recurrent or metachronous CRC was diagnosed. The quality of bowel preparation was rated according to Aronchick et al. ${ }^{21}$

\section{Outcomes}

In this study, patients were categorized into 2 groups according to the sites of index cancer. Patients with carcinoma 
of caecum, ascending colon, hepatic flexure, transverse colon and splenic flexure were considered as R-sided cancer. Those who had carcinoma of descending colon, sigmoid colon, rectosigmoid region and rectum were considered as L-sided cancer.

The primary outcome was the proportion of patients with at least 1 polyp or adenoma on surveillance endoscopies in each group. Secondary outcomes included the mean number of polyp/adenoma per patient. The association of the following factors with adenoma detection on surveillance colonoscopy was evaluated including age, sex, family history of CRC, aspirin use, statin use, stage of cancer, site of cancer, quality of bowel preparation during clearing colonoscopy, number of surveillance colonoscopy and time to last surveillance colonoscopy. Subgroup analysis was performed after exclusion of patients with carcinoma of rectosigmoid region and rectum as well as those with family history of CRC.

\section{Statistical Analyses}

Categorical variables were reported as proportions. Continuous variables were reported as mean (with 95\% CI) or median (with range) where appropriate. Comparison of continuous variables was performed using independent $t$-test, one-way ANOVA test or Mann-Whitney $U$-test. Categorical variables were compared using Pearson chi-square test or Fisher exact test. Logistic regression model was used to estimate ORs and 95\% CI of parameters to predict adenoma detection on surveillance colonoscopy. The multivariable logistic regression model included the following variables: age, sex, number of surveillance colonoscopy, time to last surveillance colonoscopy and site of index CRC. All statistical analyses were performed using SPSS version 20.0 (IBM Corp., Armonk, NY, USA). A two-sided $P$-value of $<0.05$ was considered statistically significant.

\section{RESULTS}

\section{Patients' Characteristics}

Between January 2001 and December 2004, 863 patients had undergone curative resection for CRC in Queen Mary Hospital and 390 patients were excluded for reasons as listed in Fig. 1. Among the remaining 473 patients, 327 patients had at least 1 surveillance colonoscopy after curative resection and were included in this analysis. The baseline characteristics of patients with at least 1 surveillance colonoscopy were listed in Table 1 . The quality of bowel preparation of the clearing colonoscopy was recorded in 261 patients and 234 patients $(89.7 \%)$ had their bowel preparation rated as good or fair.

\section{Surveillance Colonoscopy Findings}

A total of 474 surveillance colonoscopies were performed and the mean number of colonoscopies per patient was 1.45 (95\% CI, 1.38-1.52). The number of colonoscopy performed

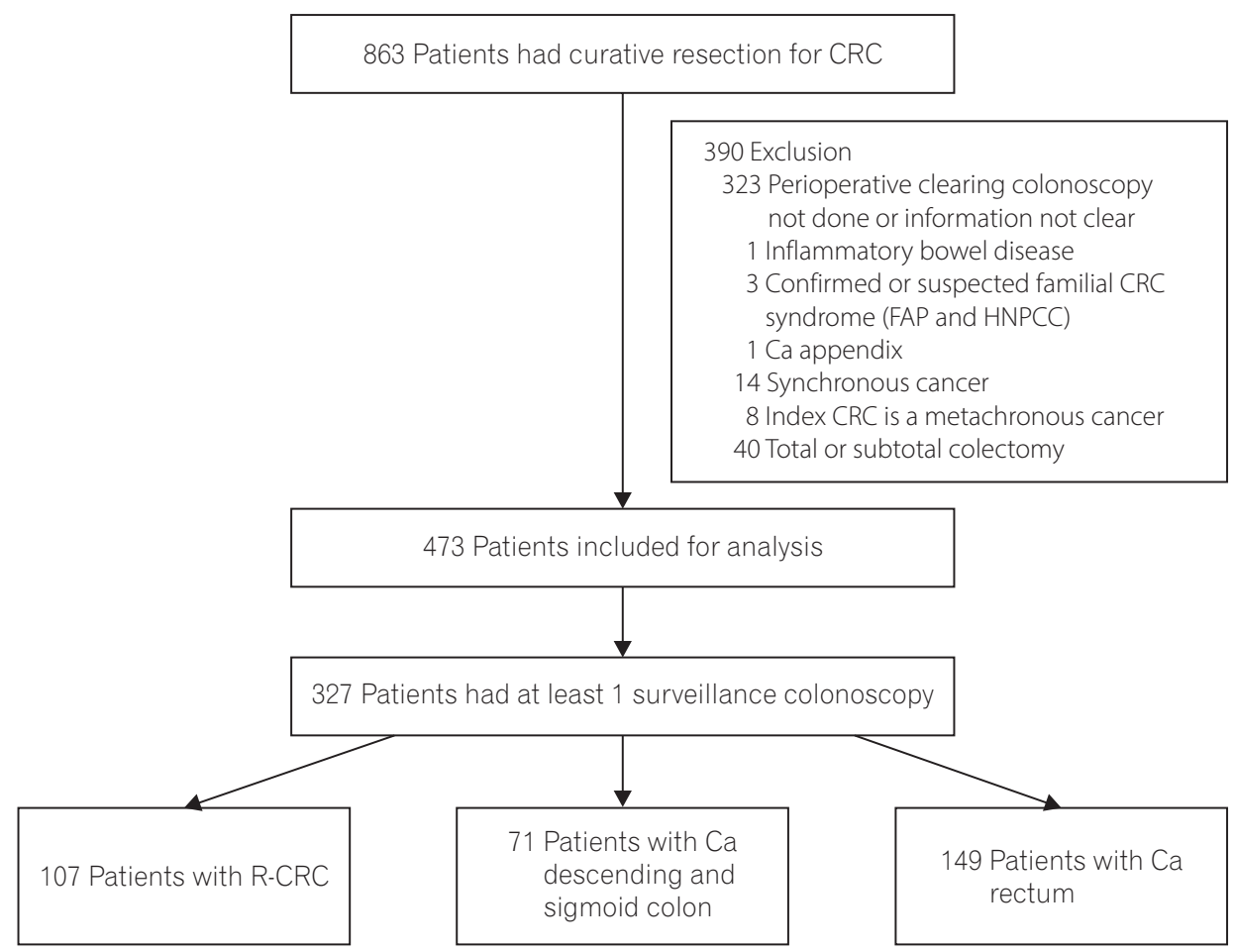

Fig. 1. Study flowchart. CRC, colorectal cancer; FAP, familial adenomatous polyposis syndrome; HNPCC, hereditary nonpolyposis colorectal cancer syndrome; $\mathrm{Ca}$, cancer; $\mathrm{R}-\mathrm{CRC}$, right-sided colorectal cancer. 
for each group was listed in Table 1. A total of 190 polyps were detected on surveillance colonoscopy. The total number of adenoma, advanced adenoma and serrated lesions were 138, 29, and 35 respectively. The distribution of colonic adenoma in the 2 groups was shown in Fig. 2.

The cumulative numbers of colonic lesions detected in each group were shown in Table 2. Both the proportions of patients with polyp or adenoma detected on surveillance colonoscopy were significantly higher in patients with Lsided cancer as compared to patients with R-sided cancer (polyps: $30.9 \%$ vs. $19.6 \%, P=0.03$ and adenoma: $25.5 \%$ vs. $13.1 \%, P=0.01$ ). Moreover, the mean number of polyp and adenoma on surveillance colonoscopy were significantly higher among patients with L-sided than patients with Rsided cancer (polyp: $0.69 ; 95 \%$ CI, $0.51-0.87$ vs. 0.36 ; $95 \% \mathrm{CI}$, $0.18-0.53 ; P=0.01$ and adenoma $0.52 ; 95 \%$ CI, $0.37-0.68$ vs. $0.22 ; 95 \%$ CI, $0.08-0.35, P<0.01)$.

However, there was no significant difference in the prevalence and number of advanced adenoma and serrated lesions between the 2 groups. Five patients with R-sided cancer (4.7\%) and 2 patients with L-sided cancer (0.9\%) had metachronous cancer detected on surveillance at a median time of 36 months (range, $11-49$ months) $(P=0.03)$.

Table 1. Baseline Characteristics of Patients

\begin{tabular}{|c|c|c|c|}
\hline & R-sided cancer $(n=107)$ & L-sided cancer $(n=220)$ & $P$-value \\
\hline Age (yr) & $68.2(66.0-70.3)$ & $65.1(63.7-66.6)$ & 0.02 \\
\hline Male sex & $54(50.5)$ & $117(53.2)$ & 0.65 \\
\hline Site of tumor & $\begin{array}{l}\text { Caecum: } 27 \text { (25.2), ascending colon: } 33 \text { (30.8), } \\
\text { hepatic flexure: } 23 \text { (21.5), transverse colon: } 17 \\
\text { (15.9), splenic flexure: } 7 \text { (8.4) }\end{array}$ & $\begin{array}{l}\text { Descending colon: } 12 \text { (5.5), sigmoid: } \\
59 \text { (26.8), recto-sigmoid: } 20 \text { (9.1), } \\
\text { rectum: } 129 \text { (58.6) }\end{array}$ & \\
\hline Family history of CRC & $3(2.8)$ & $8(3.6)$ & 0.70 \\
\hline Aspirin user & $18(16.8)$ & $30(13.6)$ & 0.45 \\
\hline Statin user & $12(11.2)$ & $21(9.5)$ & 0.64 \\
\hline Stage of CRC (\% of patients) & & & 0.99 \\
\hline $0-11$ & $73(68.2)$ & $150(68.2)$ & \\
\hline III-IV & $34(31.8)$ & $70(31.8)$ & \\
\hline Total no. of colonoscopy performed & 145 & 329 & - \\
\hline No. of colonoscopy performed per patients & $1.4(1.2-1.5)$ & $1.5(1.4-1.6)$ & 0.07 \\
\hline Time to first colonoscopy (mo) & $23.7(21.6-25.9)$ & $22.4(21.0-23.9)$ & 0.30 \\
\hline Follow-up time (mo) & $33.1(30.3-36.0)$ & $35.9(33.8-38.0)$ & 0.13 \\
\hline
\end{tabular}

Values are presented as mean $(95 \% \mathrm{Cl})$ or number $(\%)$.

$\mathrm{CRC}$, colorectal cancer.
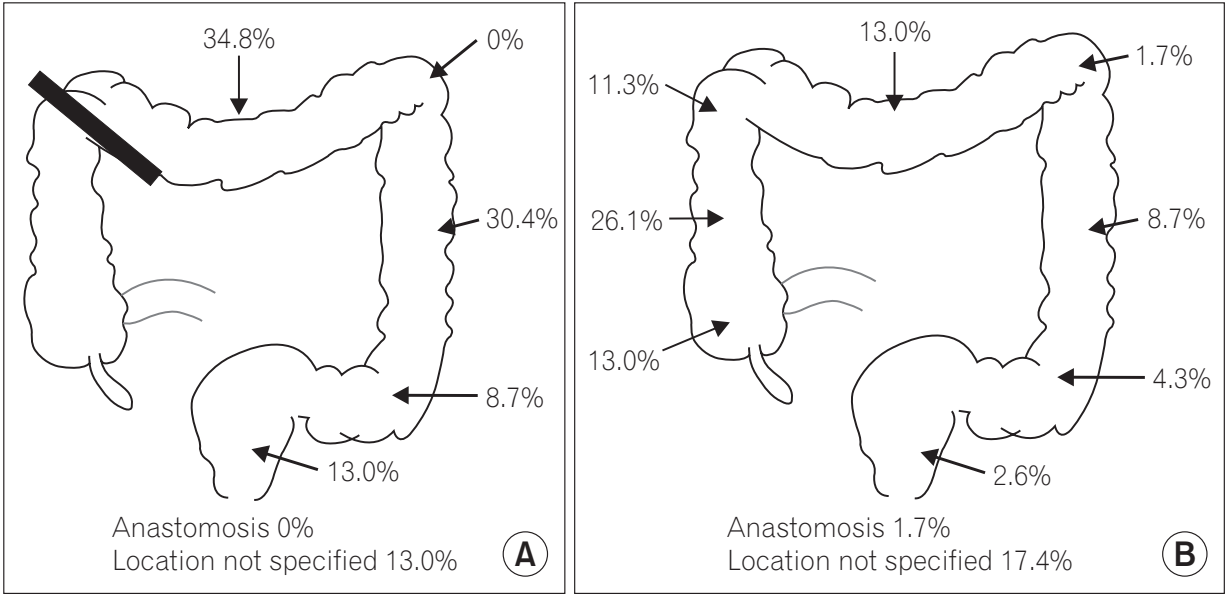

Fig. 2. Location of adenoma detected on surveillance colonoscopy. (A) Right-sided cancer: segment proximal to thick black line was removed by surgery, (B) left-sided cancer including rectal cancer. 


\section{Subgroup Analysis}

While rectal cancer patients have higher chance of local recurrence ${ }^{16}$ we performed subgroup analysis to exclude patients with cancer of rectum and rectosigmoid junction. As shown in Table 3, the differences in the detection rates of polyp and adenoma on surveillance colonoscopy between patients with R- and L-sided cancer after excluding rectal cancer were even more prominent. Fig. 3 showed the proportion of patients with different colonic lesions found on surveillance in the 3 groups of cancer patients according to primary tumor locations. The proportions of patients with metachronous polyp or adenoma was highest among patients with baseline L-sided cancer $(P<0.01)$ but were comparable between patients with baseline R-sided cancer and rectal cancer.

\section{Risk of Metachronous Adenoma}

Table 4 showed the univariate and multivariate analysis of factors associated with metachronous adenoma on surveil- lance colonoscopy. Multivariate analysis showed that Lsided cancer (OR, 2.5; 95\% CI, 1.3-5.0; $P<0.01)$, increasing

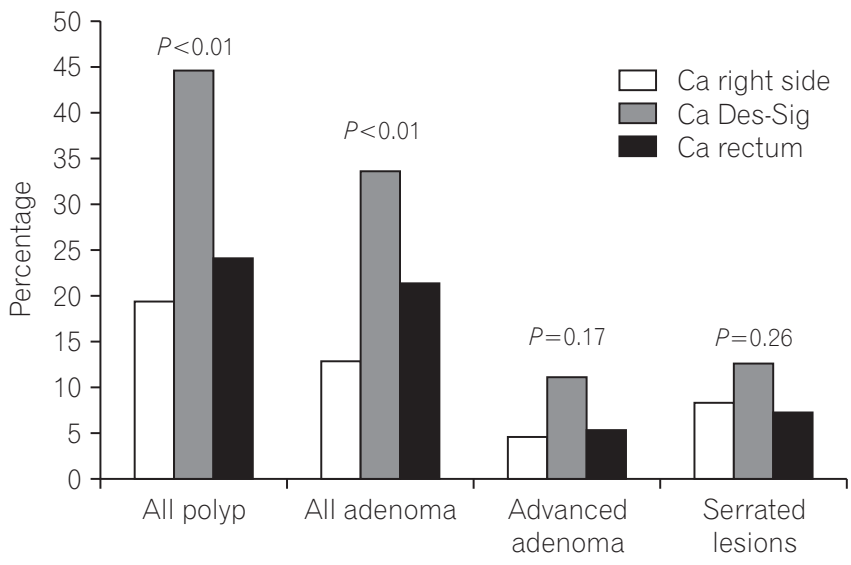

Fig. 3. Proportion of patients with polyp, adenoma, advanced adenoma, serrated lesions detected on surveillance colonoscopy according to baseline cancer location. Ca, cancer; Des-Sig, descending and sigmoid colon.

Table 2. Number of Polyp, Adenoma, Advanced Adenoma and Serrated Lesions on Surveillance Colonoscopy

\begin{tabular}{lccc}
\hline & R-sided cancer $(\mathrm{n}=107)$ & L-sided cancer $(\mathrm{n}=220)$ & $P$-value \\
\hline No. of polyp per patient & $0.36(0.18-0.53)$ & $0.69(0.51-0.87)$ & 0.01 \\
No. of adenoma per patient & $0.22(0.08-0.35)$ & $0.52(0.37-0.68)$ & $<0.01$ \\
No. of advanced adenoma per patient & $0.06(0.01-0.11)$ & $0.11(0.50-0.16)$ & 0.20 \\
No. of serrated lesion per patient & $0.11(0.04-0.19)$ & $0.11(0.06-0.15)$ & 0.84 \\
Polyp & $21(19.6)$ & $68(30.9)$ & 0.03 \\
Adenoma & $14(13.1)$ & $56(25.5)$ & 0.01 \\
Advanced adenoma & $5(4.7)$ & $16(7.3)$ & 0.37 \\
Serrated lesions & $9(8.4)$ & $21(9.5)$ & 0.74 \\
\hline
\end{tabular}

Values are presented as mean $(95 \% \mathrm{Cl})$ or number $(\%)$.

Table 3. Number of Polyp, Adenoma, Advanced Adenoma and Serrated Lesions on Surveillance Colonoscopy after Excluding Patients with Carcinoma of Rectum and Rectosigmoid Junction

\begin{tabular}{lccc}
\hline & R-sided cancer $(\mathrm{n}=107)$ & L-sided cancer $(\mathrm{n}=71)^{\mathrm{a}}$ & $P$-value \\
\hline No. of polyp per patient & $0.36(0.18-0.53)$ & $0.90(0.59-1.21)$ & $<0.01$ \\
No. of adenoma per patient & $0.22(0.08-0.35)$ & $0.65(0.39-0.91)$ & $<0.01$ \\
No. of advanced adenoma per patient & $0.06(0.01-0.11)$ & $0.14(0.03-0.25)$ & 0.16 \\
No. of serrated lesion per patient & $0.11(0.04-0.19)$ & $0.16(0.06-0.25)$ & 0.50 \\
Polyp & $21(19.6)$ & $32(45.1)$ & $<0.01$ \\
Adenoma & $14(13.1)$ & $24(33.8)$ & $<0.01$ \\
Advanced adenoma & $5(4.7)$ & $8(11.3)$ & 0.10 \\
Serrated lesions & $9(8.4)$ & $10(14.1)$ & 0.23 \\
\hline
\end{tabular}

Values are presented as mean $(95 \% \mathrm{Cl})$ or number $(\%)$.

${ }^{a}$ Excluding rectal cancer. 
Table 4. Factors Associated with Adenoma Detection on Surveillance Colonoscopy: Univariate and Multivariate Analysis

\begin{tabular}{|c|c|c|c|c|c|}
\hline & $\begin{array}{l}\text { Patients with } \\
\text { adenoma } \\
(n=70)\end{array}$ & $\begin{array}{l}\text { Patients without } \\
\text { adenoma }(n=257)\end{array}$ & $\begin{array}{c}P \text {-value } \\
\text { (univariate) }\end{array}$ & $\begin{array}{l}\text { Adjusted OR } \\
(95 \% \mathrm{Cl})\end{array}$ & $\begin{array}{c}P \text {-value } \\
\text { (multivariate) }\end{array}$ \\
\hline Age (yr) & $69.0(66.8-71.2)$ & 65.4 (63.9-66.8) & 0.01 & $1.05(1.02-1.09)^{a}$ & $<0.01$ \\
\hline Male sex & $49(70.0)$ & $122(47.5)$ & $<0.01$ & $2.70(1.50-4.90)$ & $<0.01$ \\
\hline Advanced stage of CRC (stage III or IV) & $26(37.1)$ & 78 (30.4) & 0.28 & - & - \\
\hline Positive family history & $3(4.3)$ & $8(3.1)$ & 0.32 & - & - \\
\hline Aspirin user & $12(17.1)$ & $36(14.0)$ & 0.51 & - & - \\
\hline Statin user & $10(14.3)$ & $23(8.9)$ & 0.19 & - & - \\
\hline $\begin{array}{l}\text { Bowel preparation for peri-operative } \\
\text { clearing colonoscopy rated as good }\end{array}$ & $32(45.7)$ & $114(44.7)$ & 0.84 & - & - \\
\hline More than 1 surveillance colonoscopy & $38(54.3)$ & $87(33.9)$ & $<0.01$ & $1.20(0.60-2.60)$ & 0.60 \\
\hline $\begin{array}{l}\text { Time from operation to last surveillance } \\
\text { colonoscopy (mo) }\end{array}$ & $41.0(37.3-44.7)$ & $33.4(31.5-35.2)$ & $<0.01$ & $1.03(1.01-1.06)^{b}$ & 0.02 \\
\hline L-sided cancer at baseline & $56(80.0)$ & 164 (63.8) & 0.01 & $2.50(1.30-5.00)$ & $<0.01$ \\
\hline
\end{tabular}

Values are presented as mean $(95 \% \mathrm{Cl})$ or number $(\%)$.

${ }^{a}$ Per unit increase in age.

${ }^{b}$ Per unit increase in month.

$\mathrm{CRC}$, colorectal cancer.

age (OR, 1.05; 95\% CI, 1.02-1.09; $P<0.01)$, men (OR, 2.7; 95\% CI, 1.5 $-4.9 ; P<0.01)$ and longer surveillance period (OR, 1.03; 95\% CI, 1.01-1.06; $P<0.01)$ were independent factors associated with metachronous adenoma (Table 4 ).

\section{DISCUSSION}

Our study showed that the rates of metachronous polyps or adenoma were significantly higher in patients with L-sided than R-sided cancer. The difference was even more prominent after excluding patients with rectal cancer at baseline. Multivariate analysis confirmed that L-sided cancer was an independent factor for metachronous adenoma whilst advanced age, male gender, and longer follow-up time were other significant risk factors in this cohort.

There are several explanations for the higher risk of metachronous lesions in patients with L-sided cancer after surgical resection. Firstly, some of the adenomas identified on surveillance after resection of L-sided cancer could represent "missed lesion" not detected on prior clearing colonoscopy. It is well known that screening colonoscopy is less effective for the prevention of R-sided cancer, and interval cancers are more likely to be R-sided. ${ }^{22-25}$ Study using back-to-back colonoscopies showed that R-sided adenomas were more often missed when compared to L-sided lesions. ${ }^{26}$ Second, the rate of metachronous polyp or adenoma may be related to the biology of primary tumor. Recent data showed that CRC can be classified into 4 consensus molecular subtypes based on their molecular profile. ${ }^{27}$ Some of the R-sided cancers are microsatellite unstable and their precursor lesions are serrated lesions. On the other hand, L-sided cancers are more likely associated with chromosomal instability and the precursor lesions can be adenomatous or serrated lesions. ${ }^{28}$ Further studies to evaluate the molecular characteristics of primary tumor and metachronous polyps are warranted. Third, the incidence of R-sided cancer is increasing and is even more prevalent than L-sided cancer especially in the older age group. ${ }^{29-31}$ A recent study also showed that the majority of adenomas were found in the proximal colon for patients beyond age 59 years. ${ }^{32,33}$ While the mean age of our patients was 66.1 years, the "proximal shift" of colonic neoplasia may account for the higher risk of metachronous lesions found on surveillance colonoscopy in patients with L-sided tumor. The discrepant lengths of the remaining colon after R-sided or L-sided colectomy might also influence the adenoma recurrence rate.

It is interesting to note that the rate of metachronous polyp and adenoma in patients with rectal cancer was lower than in patients with carcinoma of sigmoid and descending colon. As the proportion of patients with fair to good bowel preparation on clearing colonoscopy and mean number of surveillance colonoscopy performed in both groups were 
comparable (rectal cancer: $86.2 \%$, carcinoma of sigmoid and descending colon: $89.2 \%, P=0.51$; rectal cancer: 1.48 , carcinoma of sigmoid and descending colon: $1.52, P=0.71$ respectively), the result cannot be explained by these factors. Recent study showed that there is difference in molecular profiles of colon cancer and rectal cancer ${ }^{34}$ and the gut microbiome pattern may also change after treatment of colon tumour. ${ }^{35-37}$ We postulate that these factors may contribute to the different rates of metachronous adenoma after surgical resection of tumor at different sites.

Our study showed that the rate of metachronous cancer was higher in patients with R-sided cancer when compared to patients with L-sided cancer. R-sided CRC may harbor more microsatellite unstable tumor, which was shown to be an independent risk factor for metachronous cancer. ${ }^{4,38}$ Although this is in accordance with previous reports, ${ }^{9,11}$ the result has to be interpreted with caution as there were only 7 patients who developed metachronous cancer. Amongst the 5 R-sided cancer patients who had metachronous cancer, 1 patient had a second CRC detected at 11 months. The quality of bowel preparation of clearing colonoscopy was rated as poor in 1 patient and "not documented" in another patient. Second CRC in these patients may represent missed synchronous cancer. It is also noteworthy that for all R-sided CRC patients who developed metachronous cancer, there were no metachronous polyps detected. Similarly, precancerous lesions may be missed or resected incompletely on initial colonoscopy as a result of suboptimal bowel preparation, leading to metachronous cancer. ${ }^{39}$

Current recommendation for patients with colon cancer is to perform colonoscopy 1 year after resection, and then every 3 to 5 years depending on the last colonoscopy findings. Patients with rectal cancer are recommended to have additional sigmoidoscopy as they have a higher rate of local recurrence. ${ }^{13-16}$ As yet, there is no recommendation to stratify cancer patients into R-sided or L-sided. Intuitively, the results of our study may suggest a need to stratify surveillance colonoscopy after curative resection for R-sided or L-sided cancer. For example, young female patient with R-sided cancer may need less frequent surveillance colonoscopy after resection, while male patient with L-sided cancer may need more frequent surveillance colonoscopy. With this risk-stratified approach, a more efficient use of colonoscopy resources may be achieved.

Recently, there is increasing emphasis on the quality of colonoscopy, particularly on the adenoma detection rate. Several factors including bowel preparation, type of colonoscopes and even the endoscopists are all linked to adenoma detection rate during screening colonoscopy. ${ }^{40-43}$ In this study, the bowel preparation was rated as good to fair in $89.7 \%$ and $90.4 \%$ of the clearing colonoscopies and surveillance colonoscopies respectively, which could be considered satisfactory. Although colonoscopies were all performed by experienced endoscopists or trainees under direct supervision, the colonoscope withdrawal time was not documented in this study as many colonoscopies were performed in the period before the benefits of slow withdrawal of colonoscope come into light. ${ }^{44,45}$

Our study has other limitations. This is a retrospective study including all patients who had undergone curative colonic resection in our hospital during the defined study period. There were some differences in the baseline characteristics of the 2 groups of patients. In particular, the mean age of patients with R-sided cancer group was higher than patients with L-sided cancer (68.2 years vs. 65.1 years, $P=0.02$ ), which is not unexpected as R-sided cancer is associated with ageing. As age is also a risk factor for adenoma detection, the lower rate of metachronous polyp and adenoma in patients with R-sided tumor would support the difference found in this study was not due to difference in the mean age between the 2 groups. Second, we also included patients with rectal cancer in this study. Due to high local recurrence risk of rectal cancer, patients should undergo more regular sigmoidoscopic examination than those with more proximal cancers. Hence, there may be a chance of earlier detection of distal colonic neoplasm in these patients. Notably, we found that the rate of metachronous adenoma or polyp in patients with rectal cancer was comparable to those with R-sided cancer (Fig. 3). The difference between R-sided and L-sided cancer after excluding rectal cancer was even more significant (Table 3) and hence, our results could not be explained by the inclusion of patients with rectal cancer.

In conclusion, we found that the rate of metachronous adenoma after curative bowel resection was significantly higher in patients with prior L-sided than R-sided cancer. Lsided cancer, older age, male gender and longer follow-up time were all independently associated with metachronous adenoma detection after curative resection of CRC. Our data may support a need for the differential intervals of surveillance colonoscopy according to individual risk of metachronous adenoma, including the site of primary tumor.

\section{FINANCIAL SUPPORT}

The study was supported by the Li Shu Fun Medical Foundation and the Hui Hoy \& Chow Sin Lan Charity Fund Limited to WKL. 


\section{CONFLICT OF INTEREST}

No potential conflict of interest relevant to this article was reported.

\section{AUTHOR CONTRIBUTION}

YF Lam was involved in study concept and design, acquisition, analysis and interpretation of data and drafting of manuscript. WK Seto, KS Cheung, O Lo, I Hung and WL Law were involved in interpretation of data and critical revision of the manuscript. T Tong was involved in acquisition and interpretation of data. WK Leung was involved in study concept and design, analysis and interpretation of data, critical revision of manuscript and overall study supervision.

\section{REFERENCES}

1. Pita-Fernández S, Alhayek-Aí M, González-Martín C, LópezCalviño B, Seoane-Pillado T, Pértega-Díaz S. Intensive followup strategies improve outcomes in nonmetastatic colorectal cancer patients after curative surgery: a systematic review and meta-analysis. Ann Oncol 2015;26:644-656.

2. Fisher DA, Jeffreys A, Grambow SC, Provenzale D. Mortality and follow-up colonoscopy after colorectal cancer. Am J Gastroenterol 2003;98:901-906.

3. Rex DK, Ahnen DJ, Baron JA, et al. Serrated lesions of the colorectum: review and recommendations from an expert panel. Am J Gastroenterol 2012;107:1315-1329.

4. Leggett B, Whitehall V. Role of the serrated pathway in colorectal cancer pathogenesis. Gastroenterology 2010;138:2088-2100.

5. Hassan C, Gaglia P, Zullo A, et al. Endoscopic follow-up after colorectal cancer resection: an Italian multicentre study. Dig Liver Dis 2006;38:45-50.

6. Moon CM, Cheon JH, Choi EH, et al. Advanced synchronous adenoma but not simple adenoma predicts the future development of metachronous neoplasia in patients with resected colorectal cancer. J Clin Gastroenterol 2010;44:495-501.

7. Kawai K, Sunami E, Tsuno NH, Kitayama J, Watanabe T. Polyp surveillance after surgery for colorectal cancer. Int J Colorectal Dis 2012;27:1087-1093.

8. Rennert G, Robinson E, Rennert HS, Neugut AI. Clinical characteristics of metachronous colorectal tumors. Int J Cancer 1995;60:743-747.

9. Gervaz P, Bucher P, Neyroud-Caspar I, Soravia C, Morel P. Proximal location of colon cancer is a risk factor for development of metachronous colorectal cancer: a population-based study. Dis Colon Rectum 2005;48:227-232.
10. Mulder SA, Kranse R, Damhuis RA, Ouwendijk RJ, Kuipers EJ, van Leerdam ME. The incidence and risk factors of metachronous colorectal cancer: an indication for follow-up. Dis Colon Rectum 2012;55:522-531.

11. Ringland CL, Arkenau HT, O'Connell DL, Ward RL. Second primary colorectal cancers (SPCRCs): experiences from a large Australian Cancer Registry. Ann Oncol 2010;21:92-97.

12. Fuccio L, Spada C, Frazzoni L, et al. Higher adenoma recurrence rate after left- versus right-sided colectomy for colon cancer. Gastrointest Endosc 2015;82:337-343.

13. Kahi CJ, Boland CR, Dominitz JA, et al. Colonoscopy surveillance after colorectal cancer resection: recommendations of the US multi-society task force on colorectal cancer. Gastroenterology 2016;150:758-768.e11.

14. Meyerhardt JA, Mangu PB, Flynn PJ, et al. Follow-up care, surveillance protocol, and secondary prevention measures for survivors of colorectal cancer: American Society of Clinical Oncology clinical practice guideline endorsement. J Clin Oncol 2013;31:4465-4470.

15. Labianca R, Nordlinger B, Beretta GD, Brouquet A, Cervantes A; ESMO Guidelines Working Group. Primary colon cancer: ESMO clinical practice guidelines for diagnosis, adjuvant treatment and follow-up. Ann Oncol 2010;21 Suppl 5:v70-v77.

16. Glimelius B, Påhlman L, Cervantes A; ESMO Guidelines Working Group. Rectal cancer: ESMO Clinical Practice Guidelines for diagnosis, treatment and follow-up. Ann Oncol 2010;21 Suppl 5:v82-v86.

17. Chan EW, Lau WC, Leung WK, et al. Prevention of dabigatranrelated gastrointestinal bleeding with gastroprotective agents: a population-based study. Gastroenterology 2015;149:586-595. e3.

18. Greene FL, Page DL, Fleming ID, et al. American Joint Committee on Cancer Staging Cancer Staging Manual. 6th ed. New York: Springer, 2002.

19. Leung WK, Lo OS, Liu KS, et al. Detection of colorectal adenoma by narrow band imaging (HQ190) vs. high-definition white light colonoscopy: a randomized controlled trial. Am J Gastroenterol 2014;109:855-863.

20. Snover D, Ahnen DJ, Burt RW, et al. Serrated polyps of the colon and rectum and serrated ("hyperplastic") polyposis. In: Bozman FT, Carneiro F, Hruban RH, et al, eds. WHO classification of tumours: pathology and genetics of tumours of the digestive system. 4th ed. Berlin: Springer-Verlag, 2010:160-165.

21. Aronchick CA, Lipshutz WH, Wright SH, Dufrayne F, Bergman G. A novel tableted purgative for colonoscopic preparation: efficacy and safety comparisons with Colyte and Fleet PhosphoSoda. Gastrointest Endosc 2000;52:346-352. 
22. Samadder NJ, Curtin K, Tuohy TM, et al. Characteristics of missed or interval colorectal cancer and patient survival: a population-based study. Gastroenterology 2014;146:950-960.

23. Bressler B, Paszat LF, Chen Z, Rothwell DM, Vinden C, Rabeneck L. Rates of new or missed colorectal cancers after colonoscopy and their risk factors: a population-based analysis. Gastroenterology 2007;132:96-102.

24. le Clercq CM, Bouwens MW, Rondagh EJ, et al. Postcolonoscopy colorectal cancers are preventable: a population-based study. Gut 2014;63:957-963.

25. Robertson DJ, Lieberman DA, Winawer SJ, et al. Colorectal cancers soon after colonoscopy: a pooled multicohort analysis. Gut 2014;63:949-956.

26. Rex DK, Cutler CS, Lemmel GT, et al. Colonoscopic miss rates of adenomas determined by back-to-back colonoscopies. Gastroenterology 1997;112:24-28.

27. Guinney J, Dienstmann R, Wang X, et al. The consensus molecular subtypes of colorectal cancer. Nat Med 2015;21:1350-1356.

28. Thanki K, Nicholls ME, Gajjar A, et al. Consensus molecular subtypes of colorectal cancer and their clinical implications. Int Biol Biomed J 2017;3:105-111.

29. Rabeneck L, Davila JA, El-Serag HB. Is there a true "shift" to the right colon in the incidence of colorectal cancer? Am J Gastroenterol 2003;98:1400-1409.

30. Cucino C, Buchner AM, Sonnenberg A. Continued rightward shift of colorectal cancer. Dis Colon Rectum 2002;45:1035-1040.

31. Obrand DI, Gordon PH. Continued change in the distribution of colorectal carcinoma. Br J Surg 1998;85:246-248.

32. Patel K, Hoffman NE. The anatomical distribution of colorectal polyps at colonoscopy. J Clin Gastroenterol 2001;33:222-225.

33. Klein JL, Okcu M, Preisegger KH, Hammer HF. Distribution, size and shape of colorectal adenomas as determined by a colonoscopist with a high lesion detection rate: influence of age, sex and colonoscopy indication. United European Gastroenterol J 2016;4:438-448.

34. Salem ME, Weinberg BA, Xiu J, et al. Comparative molecular analyses of left-sided colon, right-sided colon, and rectal cancers. Oncotarget 2017;8:86356-86368.
35. Brennan CA, Garrett WS. Gut microbiota, inflammation, and colorectal cancer. Annu Rev Microbiol 2016;70:395-411.

36. Purcell RV, Visnovska M, Biggs PJ, Schmeier S, Frizelle FA. Distinct gut microbiome patterns associate with consensus molecular subtypes of colorectal cancer. Sci Rep 2017;7:11590.

37. Sze MA, Baxter NT, Ruffin MT 4th, Rogers MA, Schloss PD. Normalization of the microbiota in patients after treatment for colonic lesions. Microbiome 2017;5:150.

38. Shitoh K, Konishi F, Miyakura Y, Togashi K, Okamoto T, Nagai H. Microsatellite instability as a marker in predicting metachronous multiple colorectal carcinomas after surgery: a cohort-like study. Dis Colon Rectum 2002;45:329-333.

39. le Clercq CM, Winkens B, Bakker CM, et al. Metachronous colorectal cancers result from missed lesions and non-compliance with surveillance. Gastrointest Endosc 2015;82:325-333. e2.

40. Lebwohl B, Kastrinos F, Glick M, Rosenbaum AJ, Wang T, Neugut AI. The impact of suboptimal bowel preparation on adenoma miss rates and the factors associated with early repeat colonoscopy. Gastrointest Endosc 2011;73:1207-1214.

41. Froehlich F, Wietlisbach V, Gonvers JJ, Burnand B, Vader JP. Impact of colonic cleansing on quality and diagnostic yield of colonoscopy: the European Panel of Appropriateness of Gastrointestinal Endoscopy European multicenter study. Gastrointest Endosc 2005;61:378-384.

42. Chen SC, Rex DK. Endoscopist can be more powerful than age and male gender in predicting adenoma detection at colonoscopy. Am J Gastroenterol 2007;102:856-861.

43. Subramanian V, Mannath J, Hawkey CJ, Ragunath K. High definition colonoscopy vs. standard video endoscopy for the detection of colonic polyps: a meta-analysis. Endoscopy 2011;43:499505.

44. Lee TJ, Blanks RG, Rees CJ, et al. Longer mean colonoscopy withdrawal time is associated with increased adenoma detection: evidence from the Bowel Cancer Screening Programme in England. Endoscopy 2013;45:20-26.

45. Ross WA, Thirumurthi S, Lynch PM, et al. Detection rates of premalignant polyps during screening colonoscopy: time to revise quality standards? Gastrointest Endosc 2015;81:567-574. 